\title{
Análise do Empoderamento da Sociedade Civil no Território Rural Sul Sergipano por Meio da Análise Estratégica
}

\section{A Strategic Assessment of the Empowerment of Civil Society in the Southern Sergipe Rural Territory}

Marcos Aurélio Santos da Silva ${ }^{a}$

Neíza Cristina Santos Batistab

Sonise dos Santos Medeiros ${ }^{c}$

Deise Maria de Oliveira Galvãod

aMestre em Computação Aplicada, pesquisador da Embrapa Tabuleiros Costeiros, Aracaju, SE, Brasil

E-mail: marcos.santos-silva@embrapa.br

${ }^{b}$ Mestre em Psicologia Social, analista da Embrapa Tabuleiros Costeiros, Aracaju, SE, Brasil E-mail: neiza.batista@embrapa.br

${ }^{b}$ Mestre em Ciências da Engenharia Ambiental, analista da Embrapa Tabuleiros Costeiros, Aracaju, SE, Brasil E-mail: sonise.medeiros@embrapa.br

${ }^{b}$ Engenheira Florestal, Mestre em Ciências Florestais, analista da Embrapa Tabuleiros Costeiros, Aracaju, SE, Brasil E-mail: deise.oliveira-galvao@embrapa.br

Recebido em 10.05.2017

Aceito em 29.08.2017

ARTIGO - DOSSIÉ 


\section{RESUMO}

O Programa Nacional de Desenvolvimento Sustentável dos Territórios Rurais e o Programa Territórios da Cidadania têm como um dos principais objetivos equilibrar as relações de poder nos processos decisórios e de concertação quanto à distribuição, alocação e gestão de recursos do Governo Federal nos Territórios Rurais. Essa iniciativa de descentralização da gestão territorial e de empoderamento da sociedade civil impõem diversos desafios para os atores sociais que participam dos fóruns colegiados de discussão e de tomada de decisão, dentre eles o reequilíbrio das relações de interdependência e de poder diante de um novo contexto sociopolítico que emerge a partir da intervenção pública. Para avaliar as mudanças dessas relações no Território Rural Sul Sergipano aplicou-se a Análise Estratégica para mapear os Sistemas de Ação Concreta do território em dois períodos, 2010 e 2016. Os resultados mostraram que houve alteração das principais relações de interdependência entre os atores sociais das respectivas representações que compõem a estrutura do colegiado, permanecendo a baixa participação das diversas e outras categorias da população rural que estão para além da estrutura do colegiado.

Palavras-chave: Sociologia da Ação Organizada, política pública, poder

\section{ABSTRACT}

The National Program for the Sustainable Development of Rural Territories and the Territory of Citizenship Programme share the objective of achieving a balance of the power relations operationg in the decision-making and concertation processes, especially regarding the distribution, allocation and management of Federal Government resources to Rural Territories. This initiative of decentralization of territorial management and the empowerment of civil society impose several challenges for the social actors involved in the collegial forums of discussion. One of those challenges is the rebalancing of relations of interdependence and power in the face of a new sociopolitical context emerged from public intervention. In order to evaluate the changes of these relations in the Southern Rural Territory of Sergipe, a Strategic Analysis was applied to map the Concrete Action Systems of thisTerritory between two periods, 2010 and 2016. Results showed that the main relations of interdependence between the social actors changed in the periods analysed, but that the participation level of the various categories of the rural population remained low.

Keywords: Sociology of Organized Action, Public Policy, Power. 


\section{INTRODUÇÃO}

Desde 2003 o Governo Federal brasileiro adotou o paradigma do desenvolvimento territorial como estratégia de desenvolvimento rural por meio de dois programas coordenados pela Secretaria de Desenvolvimento Territorial (SDT) do Ministério do Desenvolvimento Agrário (MDA) ${ }^{1}$, o Programa Nacional de Desenvolvimento Sustentável dos Territórios Rurais (PRONAT) e o Programa Territórios da Cidadania (PTC). Estes programas têm como principal finalidade integrar diversas políticas públicas de combate à pobreza e desenvolvimento econômico para promover o desenvolvimento de áreas com forte desigualdade social e baixo dinamismo econômico (SABOURIN, 2015).

O PRONAT/PTC visa o equilíbrio de poder entre os diversos atores sociais, o empoderamento de classes menos favorecidas, a redução da pobreza e o aumento do dinamismo econômico, sendo que a principal estratégia adotada foi a promoção da concertação entre as diversas partes interessadas. Nesta perspectiva, o que se deseja é equilibrar as relações de poder entre o poder público e a sociedade civil nos processos decisórios e de concertação quanto à distribuição, alocação e gestão de recursos financeiros e materiais.

A heterogeneidade social, econômica e ambiental dos diversos territórios impõe dificuldades à avaliação dessas políticas públicas. Em geral, as análises sobre a efetividade do PRONAT/PTC concentram-se em estudos de casos (ZIMMERMANN et al., 2014; CANIELLO, 2016) na análise institucional (LEITE; WESZ JÚNIOR, 2012; LOTTA; FAVARETO, 2016), utilizando-se de indicadores sociais e econômicos (DELGADO; LEITE, 2011) ou fazendo a análise qualitativa das políticas territoriais comparando-as com políticas similares na América Latina (MASSARDIER; SABOURIN, 2013; SABOURIN; MASSARDIER; SOTOMAYOR, 2016).

Zimmermann et al. (2014) mostraram que, em pelo menos seis estudos de caso, prevaleceu o foco apenas na assistência social na agricultura familiar, de maneira que outras mudanças estruturais sociais necessárias não ocorreram. Segundo os autores, a inclusão da sociedade civil no debate sobre projetos territoriais não foi suficiente para suplantar os desafios inerentes a elaboração de projetos estruturantes como aqueles ligados à infraestrutura, à distribuição e diversificação de renda e criação de novos mercados.

De fato, as políticas de desenvolvimento territorial lidam com temas contraditórios, seja no Brasil ou na América Latina (SABOURIN; MASSARDIER; SOTOMAYOR, 2016). São exemplos dessa contradição: conflitos sobre o grau necessário de endogenia e afastamento da influência externa nos territórios; a importância da agricultura e o seu contraponto à diversificação das atividades econômicas; proliferação de temas e enfoques que geram diversas dificuldades em termos de manutenção do discurso em favor da política pública, de mobilização de recursos e de definição de uma estratégia eficiente e efetiva de desenvolvimento territorial.

1 Desde 29 de setembro de 2016, por meio da lei no 13.341 e do decreto no 8.865, os programa PRONAT/PTC são coordenados pela Secretaria Especial de Agricultura Familiar (SEAD), subordinada à Casa Civil., e suas Subsecretarias da Agricultura Familiar (SAF) e de Desenvolvimento Rural (SDR). 
Como destacou Lotta e Favareto (2016), os territórios tem sido usados mais como referenciais para a justaposição de políticas públicas do que para sua integração.

Lotta e Favareto (2016) reconhecem que o PRONAT/PTC procurou uma mínima articulação ministerial da distribuição dos recursos e que houve um monitoramento dos investimentos com base em metas tornadas públicas. No entanto, ainda segundo estes autores, há um alto grau de verticalidade da política pública com forte dependência dos governos federal, estadual e municipal na sua condução. Fato este que fragiliza a participação da sociedade civil.

Apesar das dificuldades, Caniello (2016) mostra que houve avanços na qualidade de vida da população rural no período entre 2003-2012 devido às políticas públicas com enfoque territorial. Segundo o autor, alimentação, moradia e renda foram os fatores melhor avaliados pela pesquisa, sendo o acesso a assitência técnica, crédito e financiamento as principais demandas dos agricultores entrevistados.

A descentralização da gestão territorial e o empoderamento da sociedade civil impõem diversos desafios para os atores sociais que participam dos fóruns sociais colegiados de discussão, dentre eles o reequilíbrio das relações de interdependência e de poder entre os atores sociais diante de um novo contexto sociopolítico mais complexo (DELGADO; LEITE, 2011). De fato, cada território desenvolve sua própria dinâmica de coalisões e conflitos buscando se adequar a novos contextos históricos. Delgado e Leite (2011) mostraram que o PRONAT/PTC pode ser considerado uma inovação institucional, mas que alguns pontos deveriam ser observados como, por exemplo, uma presença mais efetiva do Estado, a inclusão de atores ligados ao mercado, fortalecimento organizacional dos fóruns sociais e valorização de atores sociais com capacidade de mobilização das bases.

Apreende-se das avaliações do PRONAT/PTC que, além de uma avaliação crítica e positiva das políticas públicas, é necessário avaliar detalhadamente caso a caso para verificar se um novo sistema social emergiu a partir das intervenções públicas, quais novas relações sociais foram estabelecidas, quais novos atores foram agregados ao processo de tomada de decisão coletiva, se houve alterações significativas quanto aos objetivos e estratégias dos atores sociais e se, enfim, se estabeleceu um equilíbrio de forças entre a sociedade civil e o poder público nas suas três esferas. Para avaliar as mudanças dessas relações no Território Rural Sul Sergipano, Brasil, aplicou-se a Análise Estratégica a partir da Sociologia da Ação Coletiva Organizada (SACO) com o intuito de mapear os Sistemas Concretos de Ação (SCA) do Território em dois períodos, 2010 e 2016, gerando subsídios para a elaboração do Plano Territorial de Desenvolvimento Rural Sustentável, concluído em abril de 2017.

A Sociologia da Ação Coletiva Organizada (SACO) define uma organização social (por exemplo, os Colegiados de Gestão Territorial (CODETER's) como um Sistema Concreto de Ação (SCA) que emerge e se mantém a partir das diversas inter-relações entre os atores sociais por meio dos recursos compartilhados pelos mesmos (CROZIER; FRIEDBERG, 1977; FRIEDBERG, 1993). Logo, avaliar um SCA impli- 
ca na identificação desses atores e dos recursos compartilhados que motivam e condicionam esse sistema social. Ou seja, uma análise crítica da micropolítica do território, identificando as relações de poder e influência entre os atores sociais.

Este artigo está organizado da seguinte forma: a seção 2 faz uma breve revisão do uso da SACO na análise política de fenômenos rurais territorializados; a seção 3 detalha a Análise Estratégica realizada, o estudo de caso e os procedimentos gerais de pesquisa; a seção 4 apresenta e discute os resultados obtidos; e na seção 5 são apresentadas as considerações finais e conclusões.

\section{ESTUDOS CORRELATOS}

A SACO tem sido utilizada de formas distintas no espaço rural tanto no Brasil quanto na França. Os trabalhos podem ser divididos em três grupos: análise da evolução da organização social agrária no Brasil (SABOURIN, 1999); análise qualitativa/quantitativa de organizações territoriais baseadas no método de prospecção MACTOR (Matriz de Aliança e Conflitos: Táticas, Objetivos e Recomendações) (BERNOUX; BION; COHEN, 2001; GODET, 2007); e análise qualitativa e quantitativa computacional de organizações territoriais baseadas no método formal Soclab (Laboratório Sociológico) (ADREIT et al., 2009; CASULA, 2011; ROGGERO; BALDET, 2011; SIBERTIN-BLANC et al., 2013; SILVA, 2015).

Sabourin (1999) avaliou diferentes formas de ação coletiva organizada no NE brasileiro a partir das três principais lógicas de aglutinação social (sindicato, associação e cooperativa). $\mathrm{O}$ autor identificou duas fontes de poder, ou dois recursos estratégicos que podem ser mobilizados pelos atores sociais na construção de um sistema social persistente e coeso, a gestão municipal e o controle das bases. Não por acaso são recursos que se localizam nos extremos opostos, poder público e sociedade civil, respectivamente, e que são determinantes para a caracterização das situações de conflito e coalizão entre os atores sociais.

Ainda segundo Sabourin (1999), embora os agricultores familiares tenham se beneficiado desse processo de organização social é possível destacar dois problemas recorrentes. A pouca articulação com o poder público (prefeituras) e o caráter ainda não profissionalizado das diversas formas de organização social (associações, sindicatos, cooperativas). De fato, " ... a diversificação das atividades é assim associada à multiplicação das instituições e, portanto, dos centros do poder." (SABOURIN, 1999, p. 9).

Um exemplo de aplicação da Sociologia da Ação Coletiva Organizada (SACO) na análise territorial pode ser encontrado em Bernoux, Bion e Cohen (2001). Os autores utilizaram o método MACTOR (GODET, 2007), para operacionalizar os conceitos da SACO de forma que fosse possível o mapeamento e a mensuração das estratégias, antagonismos e coalisões entre os atores sociais, quando confrontados com determinada política pública. O método MACTOR, adaptado à análise territorial, procura, de fato, integrar ao diagnóstico técnico territorial ao ponto de vista político (o sistema de atores) a partir da sociologia das organizações. 
A SACO tem sido aplicada também como suporte a análises qualiquantitativas a partir da sua formalização computacional. Trata-se do método Soclab (SIBERTIN-BLANC et al., 2013; SILVA, 2015). Adreit et al. (2009) avaliaram a aceitabilidade e a aplicabilidade de políticas públicas elaboradas com fins de diminuição da poluição da bacia Adour-Garonne. Casula (2011) avaliou de forma qualitativa o processo de formação do comitê de gestão de recursos hídricos na ilha de Córsega.

O método Soclab também pode ser usado para teste de hipóteses. Por exemplo, se determinado ator social possui ou não capacidade de conduzir um processo de mudança de comportamento frente a ações de prevenção e gerenciamento de riscos de inundação na bacia do rio Touch (ROGGERO; BALDET, 2011; SIBERTIN-BLANC et al., 2013).

Desde 2008 o Território Rural Sul de Sergipe vem sendo analisado segundo a metodologia Soclab, baseada na Sociologia da Ação Coletiva Organizada. Inicialmente foram observados os conflitos entre os atores sociais ligados à agricultura familiar e aqueles ligados à conservação ambiental (SILVA, 2010, 2011; SILVA et al., 2010, 2014; TEIXEIRA et al., 2010; SILVA; SIBERTIN-BLANC; GAUDOU, 2011). Estes trabalhos tiveram como principal objetivo identificar os principais atores sociais do espaço rural e mapear conflitos relevantes entre eles. Resultados das análises quantitativas podem ser encontrados em (SILVA, 2014; SILVA et al., 2016a).

Em Silva (2015), propõe-se o uso do método Soclab para avaliação de políticas públicas territoriais, a partir dos quadros referenciais das ciências da complexidade, incluindo a abordagem de modelagem sistêmica de fenômenos complexos. De fato, o efeito local de política públicas nacionais será sempre incerto, repleto de contingências e totalmente dependente das característas culturais, geográficas, institucionais e econômicas locais.

Os métodos MACTOR e Soclab se assemelham quanto a caracterização do jogo social via identificação das alianças e de conflitos por meio da observação dos principais atores sociais, suas estratégias, interesses, poder e influência. No entanto, o método Soclab é matematicamente mais rigoroso e considera a dinâmica social como sendo baseada em dois paradigmas de comportamento social, a racionalidade limitada (SIMON, 1955) e a aprendizagem por reforço (SUTTON; BARTO, 1998).

\section{MATERIAL E MÉTODOS}

\subsection{O TERRITÓRIO RURAL SUL SERGIPANO}

O Território Rural Sul Sergipano (TRSS) foi instituído pelo MDA em 2008 a partir de uma reformulação do Território Rural Centro-Sul de Sergipe (SIQUEIRA; SILVA; ARAGÃO, 2010). O TRSS é composto de doze municípios na região Sul de Sergipe e tem como principais características a produção de laranja para a agroindústria 
local, a pecuária extensiva e o extrativismo da mangaba no litoral (Figura 1). Destacam-se também a produção de coco, mandioca, manga, fumo, maracujá, feijão e milho (SILVA et al., 2015a). Na região predomina a pequena propriedade rural em solos com baixa aptidão agrícola. Em termos de indicadores socioeconômicos o TRSS pode ser dividido em pelo menos dois agregados municipais. O primeiro que inclui os municípios de Estância, Itaporanga D'Ajuda, Salgado e Boquim com os melhores indicadores, como percentual da população em domicílios com coleta de lixo, índice de Gini e razão dos 10\% mais ricos sobre os $40 \%$ mais pobres. O segundo inclui os demais municípios que são caracterizados pelo baixo IDHM Educação e alta taxa de analfabetismo entre 18 e 24 anos (SILVA et al., 2015b).

O colegiado do TRSS (CODETER TRSS) é composto por 72 membros com direito a voto nas assembleias colegiadas, sendo que cada município indica um representante para cada uma das seis cadeiras representativas, sendo três da sociedade civil e três do poder público. O núcleo diretivo é responsável pela gestão do colegiado e conta com seis representantes, seguindo a mesma proporção das assembleias. Para prover o colegiado com suporte logístico e organizacional o MDA contratou no período de 2008 a 2014 um gestor externo, e a partir de 2015 institui o Núcleo de Desenvolvimento Territorial (NEDET) como responsável pela articulação e gestão do colegiado, por meio de chamada pública do Conselho Nacional de Desenvolvimento Científico e Tecnológico.

Durante os primeiros anos do CODETER TRSS as principais deliberações versavam sobre elaboração de projetos específicos para atender a chamadas dos Projetos de Infraestrutura e Serviços em Territórios Rurais (PROINF), Programa de Aceleração do Crescimento (PAC) ou outro programa de investimento federal. Outro ponto de pauta constante foi a forma de gestão e organização do colegiado por meio da análise permanente do regimento interno. O Plano Territorial de Desenvolvimento Rural Sustentável (PTDRS) foi elaborado e tornado público somente em abril de 2017. 


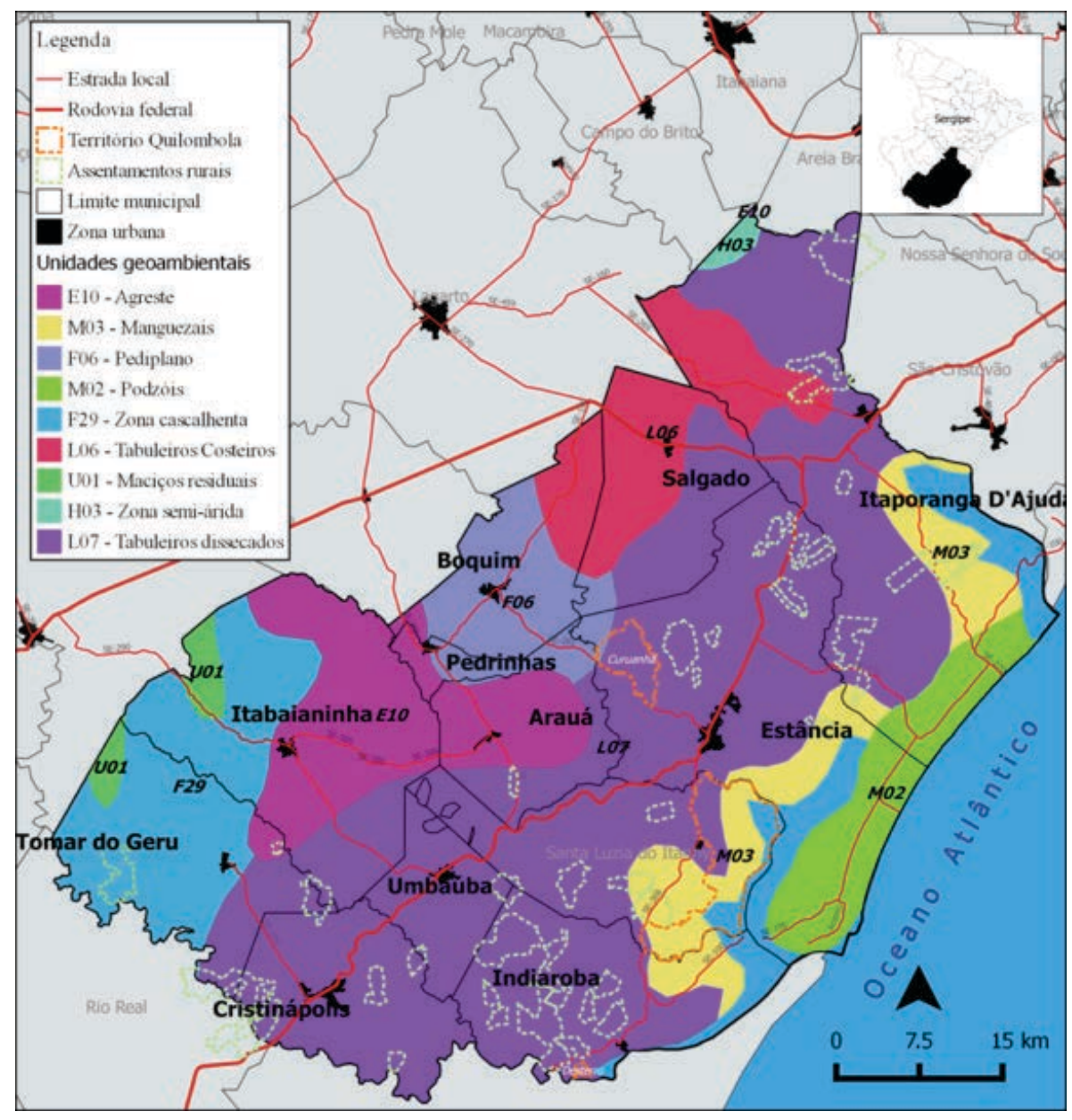

Figura 1. Território Rural Sul Sergipano com representação de informações cartográficas básicas (estradas, municípios e zonas urbanas), Territórios Quilombolas, Assentamentos Rurais e unidades geoambientais. Fonte: malha municipal 2014 (IBGE, 2014); territórios de assentamentos e quilombolas, (INCRA, 2016); rodovias federais e estaduais (SEMARH, 2014), unidades geoambientais (EMBRAPA, 2000).

\subsection{ANÁLISE ESTRATÉGICA}

A Análise Estratégica baseada na Sociologia da Ação Coletiva Organizada proposta por Crozier e Friedberg (1977) e Friedberg (1993) tem como princípios o individualismo metodológico, ou seja, o sistema social é a resultante de ações "individuais" e o racionalismo limitado (SIMON, 1955), onde o ator social define sua estratégia de acordo com o contexto social, tomando decisões, quase sempre, com alto grau de incerteza. Na Análise Estratégica o contexto social e o projeto em que estão inseridos os atores sociais são de extrema relevância. São esses dois fatores que determinarão em que grau aquele ator social estará engajado num sistema social como o colegiado territorial, por exemplo.

Cada ator social se engaja e constrói o sistema social a partir dos recursos que dispõe e que são necessários ou desejados pelos demais atores. A disponibilidade 
desse recurso e as incertezas ligadas ao seu acesso determina as zonas de incerteza "controladas" por um determinado ator social. Quanto maior essa zona de incerteza, maior será o poder de determinado ator social. Essas diversas relações de interdependência entre os atores sociais, somadas às estratégias pelas quais os atores atuam no sistema social formam o Sistema Concreto de Ação (SCA).

Logo, analisar o sistema social que constitui o Território Rural Sul Sergipano implica no inventário dos atores sociais, seus recursos e suas zonas de incerteza. Também é necessário estabelecer as conexões de interdependência entre os mesmos a partir das zonas de incerteza, e mapear as estratégias usadas por cada um, considerando que eles têm objetivos distintos, complementares, conflitantes e, por vezes, contraditórios. Ao final do processo teremos um SCA para o sistema social num determinado período que poderá ser usado para: antecipar estratégias, avaliar a capacidade de ação e poder de cada ator social, e subsidiar a elaboração do Plano Territorial de Desenvolvimento Rural Sustentável (PTDRS). O conceito de poder na Análise Estratégica é definido como a capacidade de um determinado ator influir na decisão de outro de forma que essa ação lhe seja favorável (CROZIER e FRIEDBERG, 1977).

Como demonstrado pelo método MACTOR, há diferentes formas de se estudar os SCA's. Para este estudo optou-se pelo método Soclab (SIBERTIN-BLANC et al., 2013; SILVA, 2015). O método Soclab formalizou computacionalmente a SACO de forma a ser possível a análise de cenários alternativos, a quantificação do poder e da capacidade de ação de cada ator social e o estudo da dinâmica social por meio da aprendizagem por reforço (SUTTON; BARTO, 1998). No entanto, as etapas de quantificação e simulação do método Soclab não foram consideradas nesse estudo, que se limitou à fase de identificação dos atores sociais, objetivos, recursos e estratégias.

\subsection{PROCEDIMENTOS DE PESQUISA}

O sistema social do Território Rural Sul Sergipano foi analisado a partir de dois anos de referência, 2010 e 2016. O ano de referência 2010 diz respeito ao período que se inicia em 2008, criação do Território da Cidadania Sul Sergipano, à partir do Território Rural Centro-Sul Sergipano, até o ano de conclusão do primeira análise de impacto do PRONAT/PTC no TRSS, 2010 (SILVA et al., 2014). O ano de 2016 referencia o período entre 2012 até abril de 2017, fase que marca, sobretudo, a diminuição dos recursos do PROINF, a criação do NEDET e a elaboração do PTDRS do TRSS.

A análise para o ano de referência 2010 baseia-se na reinterpretação da Análise Estratégica realizada nos trabalhos de Silva (2014), Silva et al. (2014) e Silva et al. (2016). Conforme Silva et al. (2014, p. 72), os dados desse período foram levantados por meio de uma reconstrução histórica do TRSS tendo como ponto de partida uma entrevista, sem roteiro prévio, realizada junto ao assessor do TRSS no mês de outubro de 2009. Também foram entrevistados, com base em questionário estruturado, no ano de 2010, representantes de ONG's, prefeituras, Conselhos de 
Desenvolvimento Sustentável Municipais, sindicatos e movimentos sociais, Empresa de Desenvolvimento Agropecuário de Sergipe (Emdagro), Empresa de Desenvolvimento Sustentável do Estado de Sergipe (Pronese) e Banco do Nordeste (BNB) para levantamento dos principais recursos controlados pelos mesmos, identificação de situações de conflito e de alianças permanentes e temporárias entre os mesmos. Concomitantemente, foram selecionadas 65 associações, ao acaso e considerando boa dispersão espacial, a partir da base de dados da Emdagro, nas quais foram aplicados questionários, junto aos presidentes de associações comunitárias, para levantamento da percepção do conceito de Território junto às comunidades.

Para o estudo do período de referência 2016, entre janeiro de 2016 a abril de 2017, foram realizadas pesquisas documentais nos sítios digitais do MDA (Sistema de Informação Territorial), da Emdagro (Diagnósticos Rápidos Participativos), da Secretaria de Estado da Agricultura e Desenvolvimento Rural (SEAGRI), da Embrapa Tabuleiros Costeiros (Embrapa) (Boletins do projeto Camponês a Camponês) para levantamento de dados sobre projetos em andamento, indicadores socioeconômicos e dados primários do TRSS. Estas informações subsidiaram a identificação das principais relações sobre os atores sociais.

Foram analisadas 16 atas das reuniões realizadas pelo NEDET nos anos de 2015 e 2016, e 30 ofícios de convocação das reuniões do CODETER TRSS dos período entre 2013 à 2016. Enquanto documentos de domínio público, situados como práticas discursivas, estes foram analisados sob duas perspectivas, como proposto por Spink (1999, p.126): como gênero de circulação no sentido de tornar algo público e a partir do conteúdo. Nesta última entende-se que tais documentos "são produtos em tempo e componentes significativos do cotidiano; complementam, completam e competem com a narrativa e a história". Sendo assim, partindo do conteúdo registrado nas atas e ofícios analisados, foi realizada a categorização dos principais temas discutidos, atentando-se à frequência com que foram citados e aos atores responsáveis pelo levantamento destes. Voltando-se à primeira perspectiva de análise mencionada - como gênero de circulação no sentido de tornar algo público - buscou-se a relação entre os temas mais citados e o aquele que surge como o principal tema frente ao objetivo de equilíbrio das relações de poder - a Autonomia. Como fonte de confirmação da análise realizada para o período de referência 2010, foram analisados também os relatórios de quatorze Diagnósticos Rápidos Participativos realizados pela Emdagro, em parceria com a Embrapa no ano de 2008. Esta multiplicidade de fontes metodológicas possibilitou a compreensão dos posicionamentos presentes neste coletivo em tempos diferentes e a rede de instersubjetividades construídas e reconstruídas neste período contemplando o tempo longo, o tempo vivido e o tempo curto. Além disto, inclusão de documentos públicos como fontes de informação à construção coletiva traz a responsabilização do próprio coletivo por

(...) refletir as transformações lentas em posições e posturas institucionais assumidas pelos aparelhos simbólicos que permeiam o dia-a-dia, ou, no âmbito 
das redes sociais, pelos agrupamentos e coletivos que dão forma ao informal, refletindo o ir e vir de versões circulantes assumidas ou advogadas (SPINK, 1999, 136),

possibilitando um novo diálogo com a História do Território Sul Sergipano.

Nesta perspectiva, oito boletins do projeto Camponês a Camponês - CaC, realizados entre os anos de 2012 e 2014 e o diagnóstico da Rede CaC (SILVA et al., 2016) também subsidiaram a identificação dos principais atores sociais, seus recursos e seus inter-relacionamentos para o período de referência 2016, não como uma simples sequencia de eventos, mas como uma rede de significados e práticas sociais decorrentes de uma construção histórica.

Entendendo-se que a Análise Estratégica assume posição dentro de uma proposta de Ciência Nominalista, o debate metodológico nesta pesquisa assume a abordagem ideográfica segundo a qual enfatiza-se a análise dos relatos subjetivos gerados através de um "estar dentro" das situações e do envolvimento pessoal no curso do cotidiano da vida (BURREL; MORGAN, 1979). Sendo assim, a pesquisa-ação ou pesquisa-participante referenciou toda a investigação adotada pela equipe. Logo, houve um envolvimento direto dos pesquisadores, embora sem poder de voto, durantes as plenárias e reuniões das câmaras temáticas do CODETER entre janeiro de 2015 a abril de 2017. As memórias de grande parte dessas intervenções, foram organizadas em Diários de Campo e sistematizadas em Mapas Dialógicos, como proposto por Medrado, Spink e Méllo (2014, p.273- 294) \& Nascimento, Miniguine e Pereira (2014, p.247 - 264).

Para consolidação da informação e identificação dos elementos da Análise Estratégica foram realizadas diversas oficinas entre os pesquisadores e representantes do CODETER do TRSS onde os atores sociais, seus recursos e suas inter-relações eram discutidas, definidas e validadas por consenso.

\section{RESULTADOS E DISCUSSÃO}

Embora o CODETER, por meio do regimento interno, tenha bem definida a composição do colegiado, percebe-se em seus fóruns regulares a participação ativa de atores sociais que não estão formalmente ligados a ele. Pode-se observar os principais atores ativos do TRSS, nos períodos 2010 e 2016, e seus respectivos recursos (entre parênteses) na Figura 1, sendo estes: Associação de produtores (base social e espaço rural), Prefeitura (gestão de recursos materiais e financeiros), Embrapa (projetos de pesquisa e desenvolvimento), Movimento dos Sem Terra MST (mobilização sociopolítica em assentamentos), Federação dos Trabalhadres na Agricultura do Sergipe - Fetase (mobilização sociopolítica), Instituto Nacional de Colonização e Reforma Agrária de Sergipe - INCRA (Ates), Banco do Nordeste - BNB (crédito), Sindicato dos Trabalhadores Rurais - STTR (infraestrutura e articulação da base), Emdagro (Ater) e MDA (gestão do PRONAT/PTC e PROINF). 
De acordo com a Figura 2 observa-se a atuação da Pronese no período de 2010 na assessoria de projetos financiados pelo Banco Mundial, especialmente às Associações de Produtores e ao MST, no entanto, desde 2012 a Pronese diminuiu significativamente suas atividades. Em 2015 foram criados os Núcleos de Desenvolvimento Territorial (NEDET) que além de prestarem assessoria ao CODETER, assumem junto com a Emdagro, quando the compete, a responsabilidade pela elaboração de projetos específicos e que foram priorizados e aprovados nos fóruns colegiados. A Emdagro, por sua vez, tem contribuído nas diversas etapas do processo de elaboração dos projetos junto às Associações. Em 2016 o Movimento Camponês Popular (MCP) se une ao CODETER na mobilização sociopolítica da base em torno da autonomia camponesa.



Figura 2. Atores sociais, seus principais recursos e as conexões de interdependência entre os atores via os recursos compartilhados. Fonte: elaborado pelos autores.

A Figura 2 mostra o Sistema Concreto de Ação do TRSS, exceto as estratégias de cada ator social. O diagrama, elaborado a partir dos instrumentos metodológicos mencionados nos procedimentos de pesquisa, demonstra que os atores da socie- 
dade civil mais demandados, nos dois períodos avaliados, são as associações de produtores, o MST e o STTR. Estes três atores controlam os ativos importantes na gestão social do TRSS: a articulação da base, a mobilização sociopolítica, e, no caso do MST e das Associações, o acesso ao espaço rural. A principal zona de incerteza explorada por esses atores é o comportamento social da base que os mesmos "influenciam". Quando se avalia o poder público percebe-se que os atores mais demandados e ativos são a Emdagro (Empresa de Desenvolvimento Agropecuário de Sergipe) e a Embrapa (Empresa Brasileira de Pesquisa Agropecuária). A Emdagro tem escritórios de Ater em quase todos os municípios do TRSS e é membro do núcleo diretivo do CODETER. A Embrapa participa do colegiado, principalmente na câmara temática de inclusão produtiva e agroecologia por meio da proposição de projetos e "animação" dos processos de gestão da câmara. O MDA, por meio dos assessores até 2014, e via NEDET desde 2015, fornecendo apoio logístico e gerencial ao CODETER. Destaca-se o papel do NEDET, que além de agregar a competência de equipes acadêmicas, agrega também atores que pertencem a região circunscrita ao Território, com acesso direto às comunidades, trazendo questões locais, aproximando as decisões colegiadas da realidade local. As prefeituras são de extrema importância para o TRSS em função de controlar o recurso estratégico "gestão de recursos materiais e financeiros", fundamentais para a execução do PROINF. No entanto, apesar da sua importância são poucas as prefeituras que tem participação efetiva nas plenárias do colegiado.

A Análise Estratégica para o período 2010 mostrou que (Silva et al., 2016, p. 5-6):

a) as relações entre as associações comunitárias e de produtores são mais intensas com a Emdagro, Pronese e prefeituras; b) as entidades ligadas à conservação ambiental apresentaram baixo grau de comunicação e interação com o TRSS; c) a pesquisa, por amostragem, em 65 associações comunitárias e de produtores da agricultura familiar mostrou que é baixo o nível de participação ou de engajamento das mesmas com o colegiado territorial; d) alguns atores sociais importantes para o processo de desenvolvimento sustentável do território mostraram baixa intensidade de cooperação ou comunicação com os demais atores sociais; e) há um certo conflito entre as políticas municipais e as estaduais; f) os atores sociais, apesar de [apresentarem] divergências, têm expectativa de um jogo social cooperativo; e g) o sistema socioterritorial TRSS é de certa forma estável, apesar das fragilidades.

Para o período 2016, tem-se que: persiste a completa ausência de entidades ligadas a questão do ambiente no CODETER, apesar de inserções pontuais na pauta de discussão sobre o tema; há uma forte coalizão entre os movimentos sociais, sobretudo o MST, e o STTR/Fetase quanto à defesa do PRONAT/PTC; algumas prefeituras se posicionam contra o projeto PRONAT/PTC, mesmo que os conflitos não se estabeleçam de forma direta; houve novas adesões de movimentos sociais com destaque para os Quilombolas e o MCP; as dificuldades de gestão dos recursos do PROINF permanecem, principalmente nos itens elaboração de projetos por parte do CODETER e execução por parte do poder público; também permanece a dificuldade de integração de ações do poder público, tanto entre ministérios 
como entre os poderes federal, municipal e estadual; há dependência da articulação e animação do CODETER por parte do MDA, agora via NEDET.

Para os dois períodos nota-se a importância da reciprocidade direta como fonte de criação e manutenção de elos de confiança interpessoais, que terminam por influenciar ou condicionar as relações entre os atores sociais. Ou seja, as organizações públicas e da sociedade civil são representadas por indivíduos que participam dos circuitos de reciprocidade, sendo esta decisiva no momento da definição das decisões entre os atores. Dentre as ações dos atores sociais destacam-se: a atuação da Embrapa como animadora da câmara temática de agroecologia e responsável pela elaboração de projetos agroecológicos como o Camponês a Camponês (SILVA et al., 2016b); a participação seletiva das prefeituras nas plenárias, priorizando projetos e ações de seu próprio interesse; o envolvimento propositivo e constante da Emdagro e do Banco do Nordeste; e o grau elevado de atividade dos movimentos sociais no CODETER, o que tem garantido a condução da pauta de discussões do colegiado.

A partir da Análise Estratégica dos dois períodos sugere-se um plano de ação que considere: a definição de um mecanismo autônomo de animação do TRSS como, por exemplo, a coordenação rotativa do CODETER, por suas instituições constituintes; a criação de uma equipe multidisciplinar permanente para elaboração de estudos e projetos territoriais com suporte da Embrapa, Emdagro, Governo Estadual, Universidade Federal de Sergipe (UFS), Escritório Técnico de Estudos Econômicos do Nordeste do BNB, Instituto Federal de Sergipe (IFS) e associações; e a flexibilização do regimento interno, facilitando assim novas adesões, principalmente de novos movimentos sociais, Serviço Brasileiro de Apoio às Micro e Pequenas Empresas e entidades ambientais.

\section{CONCLUSÕES}

A proposta metodológica utilizada nesta pesquisa, possibilitou uma aproximação da rede em constante movimento que representa o CODETER e a coconstrução de sentidos variados junto aos atores que a constituem por meio de formas diversas de discursos: atas, documentos de domínio público como o regimento interno, conversas e posicionamentos nas reuniões do próprio colegiado e das câmaras temáticas. Quando analisados os períodos de 2010 e 2016, observam-se poucas alterações quanto à exclusão e inserção de novos atores, no entanto, destaca-se a importância da revisão do regimento interno de forma que este se mostre consoante com a dinâmica do CODETER e agregue atores importantes a este movimento. Um aspecto importante a ser ainda trabalhado quanto aos objetivos do PRONAT/PTC se refere à necessidade de trabalhar estratégias de promoção de autonomia junto a esta rede, haja vista que nos períodos analisados as ações dos atores focaram-se principalmente na organização interna do Colegiado, de maneira que 2016 preserva ainda muitos dos problemas diagnosticados em 2010. As 
coalizões e oposições no CODETER são bem definidas. O NEDET como assessor territorial congregando a UFS, o IFS e a Embrapa agregou valor ao processo de condução e animação do CODETER, principalmente no seu compromisso de elaboração do PTDRS.

\section{REFERÊNCIAS}

ADREIT, F. et al. Prendre en compte la dimension sociale dans un projet de développement durable : fondements et utilisation du système Soclab. In: Systèmes d'Information et de Décision pour l'Environnement, SIDE'09, Toulouse. Anais... Toulouse: Association Inforsid, 2009.

BERNOUX, P.; BION, J.-Y.; COHEN, J.-C. L'analyse des systèmes d'acteurs : Cahier 1 - Diagnostics des territoires. Lyon: CERTU - Centre d'Etudes sur les Réseaux, les Transports, I'Urbanisme et les constructions publiques, 2001.

BURREL, G and MORGAN, G. Sociological paradigms and organizational analiysis. London, Heinemann, 1979.

CANIELLO, M. Identidade e qualidade de vida nos Territórios da Cidadania. Sociologias, v. 18, n. 43, p. 300-334, 2016. Disponível em: <http://dx.doi. org/10.1590/15174522-018004313>. Acesso em: 10 nov. 2016.

CASULA, M. Innovation politique et changement organisationnel dans la gestion de l'eau : la création du Comité de Bassin de Corse. In: Congrès de l'Association Française de Sociologie, GT32 Sociologie des systèmes complexes, Grenoble. Anais... Grenoble: AFS, 2011.

CROZIER, M.; FRIEDBERG, E. L'acteur et le système. Paris: Seuil, 1977.

DELGADO, N. G.; LEITE, S. P. Políticas de desenvolvimento territorial no meio rural brasileiro: novas institucionalidades e protagonismos dos atores. Dados - Revista de Ciências Sociais, v. 54, n. 2, p. 431-473, 2011. Disponível em: <http://dx.doi. org/10.1590/S0011-52582011000200007>. Acesso em: 2 ago. 2015.

EMPRESA BRASILEIRA DE PESQUISA AGROPECUÁRIA - EMBRAPA. Zoneamento Agroecológico do Nordeste - ZANE Digital. Petrolina : Embrapa Solos, 2000. Documentos n. 14. CD ROM.

FRIEDBERG, E. O poder e a regra: dinâmicas da ação organizada. Lisboa: Instituto Piaget, 1993.

GODET, M. Manuel de prospective stratégique : Tome 2 - L'Art et la méthode. 3. ed. Paris: DUNOD, 2007. 
INSTITUTO BRASILEIRO DE GEOGRAFIA E ESTATÍSTICA - IBGE. Malhas digitais municipais. 2014. Disponível em: <http://mapas.ibge.gov.br>. Acesso em: 7 jul. 2016.

INSTITUTO NACIONAL DE COLONIZAÇÃO E REFORMA AGRÁRIA (INCRA). Banco de dados de assentamento e territórios quilombolas. 2016.

LEITE, S. P.; WESZ JÚNIOR, V. J. Um estudo sobre o financiamento da política de desenvolvimento territorial no meio rural brasileiro. Revista de Economia e Sociologia Rural, v. 50, n. 4, p. 645-666, 2012. Disponível em: <http://dx.doi. org/10.1590/S0103-20032012000400004>. Acesso em: 13 abr. 2014.

LOTTA, G.; FAVARETO, A. Desafios da integração nos novos arranjos institucionais de políticas públicas no Brasil. Revista de Sociologia e Política, v. v. 24, , n. i, p. 49-65, 2016. Disponível em: <http://dx.doi.org/10.1590/1678-987316245704>. Acesso em: 6 dez. 2016.

MASSARDIER, G.; SABOURIN, E. Internationalization and dissemination of rural territorial development public policies : model hypotheses for Latin America. Sustentabilidade em Debate, v. 4, n. 2, p. 83-100, 2013. Disponível em: <http:// dx.doi.org/10.18472/SustDeb.v4n2.2013.9489>. Acesso em: 17 jun. 2014.

MEDRADO, B.; SPINK, M. J; MÉLLO, R.P. Diários como atuantes em nossas pesquisas: narrativas ficcionais implicadas. In: SPINK, M. J. et al. (Org.). A Produção de Informação na Pesquisa Social: compartilhando ferramentas. Rio de Janeiro: Centro Edelstein de Pesquisas Sociais, 2014.

NASCIMENTO, V.L.V. do; TAVANTI, R. M.; PEREIRA, C. C. Q. O uso de mapas dialógicos como recurso analítico em pesquisas científicas. In: SPINK, M. J. et al. (Org.). A Produção de Informação na Pesquisa Social: compartilhando ferramentas. Rio de Janeiro: Centro Edelstein de Pesquisas Sociais, 2014.

ROGGERO, P.; BALDET, B. Positionnements stratégiques autour du risque d'inondation : modélisation et simulation du cas de la vallée du Touch en Haute-Garonne. In: Congrès de I'Association Française de Sociologie, GT32 Sociologie des systèmes complexes, Grenoble. Anais... Grenoble: AFS, 2011.

SABOURIN, E. P. Ação coletiva e organização dos produtores no Nordeste Semi-Árido. In: 37o Congresso Brasileiro de Economia e Sociologia Rural, Cascavel. Anais... Cascavel: SOBER, 1999.

SABOURIN, E. P. Politiques de développement rural territorial au Brésil : entre participation et clientélisme. Esprit Critique, v. 21, n. 1, 2015. 
SABOURIN, E. P.; MASSARDIER, G.; SOTOMAYOR, O. As políticas de desenvolvimento territorial rural na América Latina: uma hibridação das fontes e da implementação. Revista Latinoamericana de Políticas y Acción Pública, v. 3, n. 1, p. 75-98, 2016. Disponível em: <http://dx.doi.org/10.17141/mundosplurales.1.2016.2319>. Acesso em: 21 nov. 2016.

\section{SEMARH. Banco de Dados Geográfico de Sergipe. 2014.}

SIBERTIN-BLANC, C. et al. SocLab: A Framework for the Modeling, Simulation and Analysis of Power in Social Organizations. Journal of Artificial Societies and Social Simulation, v. 16, n. 4, p. 1-30, 2013. Disponível em: <http://dx.doi. org/10.18564/jasss.2278>. Acesso em: 15 jul. 2014.

SILVA, M. A. S. da. Social modeling of competing claims on natural resources: family farming versus environmental conservation. In: 3rd World Congress on Social Simulation, Kassel. Anais... Kassel: Center for Environmental Systems Research, University of Kassel, 2010.

SILVA, M. A. S. da. Développement durable et jeux d'acteurs d'un territoire rural dans le Sud de Sergipe (Brésil). In: IV Congrès de l'Association Française de Sociologie, Grenoble. Anais... Grenoble: UPMF, 2011.

SILVA, M. A. S. da. Modeling and simulation of a socioterritorial system: an exploratory analysis of the Southern Rural territory of Sergipe, Brazil. In: Brazilian Workshop on Social Simulation, São Paulo, Brasil. Anais... São Paulo, Brasil: UFRG, 4 nov. 2014.

SILVA, M. A. S. da. O território como um sistema social complexo. In: FURTADO, B. A.; SAKOWSKI, P. A. M.; TÓVOLLI, M. H. (Ed.). Modelagem de sistemas complexos para políticas públicas. 1. ed. Brasília: Instituto de Pesquisa Econômica Aplicada, 2015. p. 403-436.

SILVA, M. A. S. da et al. Regionalização da área de atuação da Embrapa Tabuleiros Costeiros a partir do algoritmo SKATER. Aracaju: Embrapa Tabuleiros Costeiros, 2015a.

SILVA, M. A. S. da et al. Análise da autocorrelação espacial das principais atividades agropecuárias na área de atuação da Embrapa Tabuleiros Costeiros. Aracaju: Embrapa Tabuleiros Costeiros, 2015b.

SILVA, M. A. S. da et al. Modelagem social computacional como instrumento de análise de sistemas sociais territoriais complexos. Campo - Território, v. 9, n. 17, p. 55-85, 1 abr. 2014. Disponível em: <http://www.seer.ufu.br/index.php/campoterritorio/article/view/22488>. Acesso em: 10 out. 2015. 
SILVA, M. A. S. da et al. Análise exploratória de simulações sociais computacionais por meio de estatística multivariada e mapas auto-organizáveis. Scientia Plena, v. 12, n. 7, 2016a. Disponível em: < http://dx.doi.org/10.14808/sci.plena.2016.071301 >. Acesso em: 30 set. 2016.

SILVA, M. A. S. da; SIBERTIN-BLANC, C.; GAUDOU, B. Modélisation des processus sociaux pour le développement rural durable. In: Colloque National - Ecologisation des politiques et des pratiques agricoles, Avingon. Anais... Avingon: INRA PACA, 2011.

SILVA, M. A. S. da et al. Modelagem social como instrumento de análise de demandas conflitantes em territórios rurais. In: Simpósio sobre Inovação e Criatividade Científica na Embrapa, Brasília, DF. Anais... Brasília, DF: Embrapa, 2010.

SILVA, M. A. S. da et al. Social network analysis of agroecological knowledge construction in areas of settled farmers in Sergipe , Brazil. Aracaju: Embrapa Tabuleiros Costeiros, $2016 \mathrm{~b}$.

SIMON, H. A. A behavioral model of rational choice. Quaterly Journal of Economics, v. 69, p. 99-118, 1955.

SIQUEIRA, E. R. de; SILVA, M. A. S. da; ARAGÃO, A. G. de. O território rural centro-sul de Sergipe. Aracaju: Embrapa Tabuleiros Costeiros, 2010.

SPINK, Peter. Análise de Documentos de Domínio Público. In: SPINK, Mary Jane (org). Práticas Discursivas e Produção de Sentidos no Cotidiano. São Paulo: Cortez, 1999.

SUTTON, R. S.; BARTO, A. G. Reinforcement learning: an introduction. Cambridge: MIT Press, 1998.

TEIXEIRA, O. A. et al. A la recherche d'une méthode pour la modélisation des processus de développement ruraux. In: Symposium on Innovation and Sustainability Development in Agriculture and Food, Montpellier. Anais... Montpellier: Cirad-Inra-SupAgro, 2010.

ZIMMERMANN, S. A. et al. Desenvolvimento Territorial e políticas de enfrentamento da pobreza rural no Brasil. Campo - Território : Revista De Geografia Agrária, v. 9, n. 17, p. 540-573, 2014. Disponível em: <http://www.seer.ufu.br/ index.php/campoterritorio/article/view/23828>. Acesso em: 14 jul. 2015. 